\title{
Coccidioidomycosis in armadillo hunters from the state of Ceará, Brazil
}

\author{
Raimunda Sâmia Nogueira Brillhante ${ }^{1,2} /{ }^{+}$, Renato Evando Moreira Filho ${ }^{1,2}$, \\ Marcos Fábio Gadelha Rocha ${ }^{1,2,3}$, Débora de Souza Collares Maia Castelo-Branco', \\ Maria Auxiliadora Bezerra Fechine ${ }^{1}$, Rita Amanda Chaves de Lima ${ }^{1,2}$, Yuri Vieira Cunha Picanço ${ }^{5}$, \\ Rossana de Aguiar Cordeiro ${ }^{1,2}$, Zoilo Pires de Camargo ${ }^{6}$, José Ajax Nogueira Queiroz ${ }^{4}$, \\ Roberto Wagner Bezerra de Araujo ${ }^{4}$, Jacó Ricarte Lima de Mesquita ${ }^{5}$, José Júlio Costa Sidrim,2
}

\author{
${ }^{1}$ Centro Especializado em Micologia Médica ${ }^{2}$ Programa de Pós-graduação em Microbiologia Médica \\ ${ }^{4}$ Departamento de Patologia e Medicina Legal, Faculdade de Medicina, Universidade Federal do Ceará, Fortaleza, CE, Brasil \\ ${ }^{3}$ Programa de Pós-graduação em Ciências Veterinárias, Universidade Estadual do Ceará, Fortaleza, CE, Brasil \\ ${ }^{5}$ Hospital São José de Doenças Infecciosas, Fortaleza, CE, Brasil ${ }^{6}$ Universidade Federal de São Paulo, São Paulo, SP, Brasil
}

Coccidioidomycosis is a systemic mycosis with a variable clinical presentation. Misdiagnosis of coccidioidomycosis as bacterial pneumopathy leads to inappropriate prescription of antibiotics and delayed diagnosis. This report describes an outbreak among armadillo hunters in northeastern Brazil in which an initial diagnosis of bacterial pneumonia was later confirmed as coccidioidomycosis caused by Coccidioides posadasii. Thus, this mycosis should be considered as an alternative diagnosis in patients reporting symptoms of pneumonia, even if these symptoms are only presented for a short period, who are from areas considered endemic for this disease.

Key words: pneumonia - coccidioidomycosis - micro-epidemic - diagnosis

Coccidioidomycosis is a systemic infection caused by the dimorphic fungi Coccidioides immitis and Coccidioides posadasii. It can occur as a severe disease that can be fatal (Capilla et al. 2009). Approximately 40\% of cases occur as a pneumopathy that is difficult to differentiate from bacterial pneumonia, which can lead to the inappropriate prescription of antibiotics and delayed diagnosis (Ampel 2010).

It is estimated that there are approximately 50,000 cases of coccidioidomycosis requiring medical treatment annually in the United States (Stern \& Galgiani 2010). In Brazil, coccidioidomycosis is an endemic disease in the semi-arid region of the country (Sidrim et al. 1997, Cordeiro et al. 2006b, 2010). This paper reports an outbreak in this region among armadillo hunters, with diagnosis based on epidemiological characteristics and confirmed by laboratory techniques. This research was approved by the human research Ethical Committee of São José Hospital of Infectious Diseases (protocol 22/2011).

The cases occurred in the municipality of Santa Quitéria ( $\left.4^{\circ} 19^{\prime} 55^{\prime \prime} \mathrm{S} 40^{\circ} 9^{\prime} 25^{\prime} \mathrm{W}\right)$ in the state of Ceará (CE). In June 2010, a father and son, aged 48 and 13 years, respectively, were hospitalised in a facility specialising in infectious diseases after presenting fever, thoracic pain, coughing and dyspnoea for the previous 11 days.

Financial support: CNPq (307952/2008-8), PROTAX

(562296/2010-7), CAPES, PNPD (2103/2009)

+ Corresponding author: brilhante@ufc.br

Received 13 December 2011

Accepted 10 May 2012
Pulmonary auscultation demonstrated bilateral crepitations. The patients were hospitalised for four days in Santa Quitéria with a diagnosis of bacterial pneumonia. Ceftriaxone was prescribed with no improvement. Admission tests included radiographs revealing perihilar and basal infiltrates and inconclusive biochemical and haematological tests. In the 13-year-old patient, a thoracic ultrasound revealed pleural effusion with a volume of $380 \mathrm{~mL}$. The attending staff requested an immunological and mycological evaluation from the Specialized Centre for Medical Mycology (CEMM) of the Federal University of Ceará (UFC).

The therapy was then changed to amphotericin B (50 mg/day, intravenously). Both patients improved and were released from the hospital and prescribed fluconazole $(450 \mathrm{mg}$ and $300 \mathrm{mg}$ /day, orally, for father and son, respectively). The staff at CEMM analysed the collected clinical specimens within a level 3 biosecurity structure. Additionally, a group of qualified professionals from CEMM went to Santa Quitéria to identify for new cases of the disease. Blood samples were taken from 13 armadillo hunters in the region and from one dog that accompanied them. Soil samples were also collected from the hunting site.

In July 2010, one of these hunters, a 46-year-old man, was hospitalised at the same hospital, suffering from thoracic pain associated with fever and night sweating for the previous 21 days. Pulmonary auscultation showed no alterations. Trimethoprim/sulphamethoxazole and cephalexin were prescribed, with no improvement. Admission tests included radiographs with nodular opacities in the pulmonary parenchyma and nonspecific biochemical and haematological tests. A sputum culture was performed on Sabouraud agar in the hospital laboratory and revealed 
colonies compatible with C. posadasii. The material was sent to the CEMM. Treatment with fluconazole $(400 \mathrm{mg} /$ day, intravenously) was initiated and after five days the patient no longer reported clinical symptoms.

At CEMM, sputum samples from the three cases were assessed by microbiological examination. Optical microscopy of the clinical specimens revealed spherules with thick cell walls containing and releasing endospores (Figure). Subsequently, the clinical specimens from the three patients were cultured on Sabouraud agar, Sabouraud supplemented with chloramphenicol and Sabouraud supplemented with chloramphenicol and cycloheximide, each of which resulted in the growth of white, cotton-like colonies.

Radial immunodiffusion tests were performed against the commercial antigen of Coccidioides sp. produced by Immy Immunodiagnostics and against the in-house antigen produced by CEMM (Brilhante et al. 2008). The radial immunodiffusion assay yielded positive reactions for four of the armadillo hunters ( 3 of whom had been hospitalised) against the Immy Immunodiagnostics antigen as well as the antigen prepared in-house. The serum samples from the dog and the other hunters were negative.

Furthermore, the three isolates were identified by single polymerase chain reaction (PCR) with the primers Coi9-1F and Coi9-1R (Umeyama et al. 2006), according to the methodology described by Cordeiro et al. (2010). The PCR amplified a 634-bp sequence, which indicated the presence of the species C. posadasii, in all samples. Additionally, the $18 \mathrm{~S}-28 \mathrm{~S}$ region of the nuclear ribosomal DNA was sequenced. Initially, this region was amplified with the primers ITS4 and ITS5, as described by White et al. (1990). The amplification products were visualised by $1 \%$ agarose gel electrophoresis. Once the specificity of the amplification was confirmed, the PCR products were purified with GFX PCR DNA and Gel Band Purification kits (GE Healthcare Life Sciences, Buckinghamshire, UK). DNA sequencing was performed with

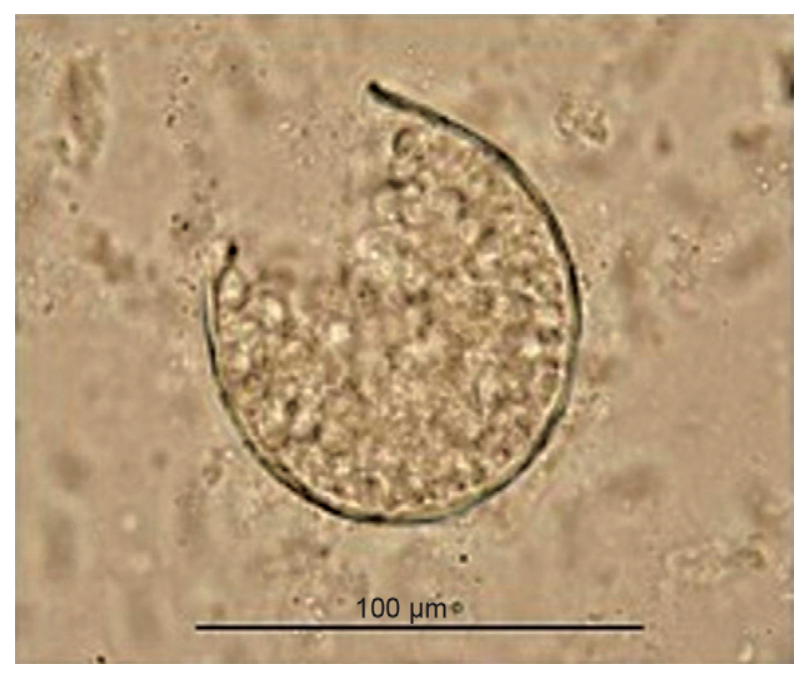

Aspect of a spherule of Coccidioides posadasii in a direct examination by optical microscopy in the sputum of a hospitalized patient.
GFX $^{\mathrm{TM}}$ PCR DNA and gel band purification kits (GE Healthcare Life Science, Buckinghamshire, England), following the protocol provided by the manufacturer. Sequencing reactions were then analysed in a MegaBACE 1000 automatic sequencer (GE Healthcare Life Sciences, Buckinghamshire, UK). Sequences were identified by similarity with isolates previously deposited in GenBank (ncbi.nlm.nih.gov/Genbank), as determined by BLAST (Altschul et al. 1990). The molecular analysis of the strains from the hospitalised patients demonstrated the presence of sequences that were $100 \%$ identical to those of $C$. posadasii deposited in GenBank.

The association between armadillo hunting and coccidioidomycosis is well-documented in the literature (Sidrim et al. 1997, Cordeiro et al. 2010). Therefore, tests for this mycosis should be performed on patients from endemic areas who report, even for a short period, symptoms of pneumonia (Kwok et al. 2009). Clinical diagnosis of coccidioidomycosis can be difficult (Kim et al. 2009), particularly in regions that are endemic for tuberculosis, such as CE, making laboratory analysis mandatory.

Serological tests are relatively easy to perform and do not require hazardous direct handling of the fungus (Saubolle et al. 2007). Four of the sera tested were positive for coccidioidomycosis. These results confirm the applicability of this method to epidemiological inquiries in endemic areas.

Research efforts have been directed at developing more rapid and specific methods to diagnose this disease, such as molecular biological techniques (Cordeiro et al. 2006a , Castanon-Olivares et al. 2007). The identification by PCR reported here confirmed the mycological diagnosis rapidly and safely.

Nineteen soil samples from the hunting site were processed (Sidrim et al. 1997). After approval by the animal research Ethical Committee of UFC (protocol 77/09), male Swiss mice were inoculated intraperitoneally with a suspension containing the soil samples and then observed for 15 days. Blood samples were taken from the animals for radial immunodiffusion against the Coccidioides $\mathrm{sp}$. antigen. The mice were euthanized and fragments were removed from the lungs, liver and spleen. These were cultured onto potato dextrose agar and subjected to histopathological analysis. However, the immunodiffusion assay did not produce any positive results and culture of the sampled organs did not demonstrate any fungal growth. The histopathological analysis only indicated a nonspecific acute inflammatory process.

The investigation of soil samples from endemic areas is important, considering that digging is typical of armadillo hunting and causes the dissemination of fungal conidia, facilitating their inhalation (Sidrim et al. 1997). Some studies have shown that the frequency of sick individuals can be as high as $90 \%$ after earthquakes or among workers performing excavation at building or archaeological sites (Schneider et al. 1997, Crum et al. 2004). The use of animal models to demonstrate the presence of Coccidioides spp in soil samples has been described by several authors, such as Greene et al. (2000), but a low fungal recovery rate is obtained from this type of sample (Egeberg et al. 1964, Elconin et al. 1964). The 
recovery rate can be improved with the use of molecular tools such as semi-nested PCR (Macêdo et al. 2011) and multiplex PCR (Lauer et al. 2012).

It is important to state that all of the hospitalised patients were hunting together at the same site within an endemic municipality, which may indicate that this particular site presents a higher concentration of conidia. The armadillo hunting described was performed in a region with appropriate conditions for fungal development, including a semi-arid climate, rainfall below $800 \mathrm{~mm} /$ year, high temperatures, extended periods of drought, alkaline soils and xerophytic vegetation (IPECE 2007).

Additionally, the incidence of coccidioidomycosis continues to increase and primary coccidioidal pneumonia accounts for $17-29 \%$ of all cases of communityacquired pneumonia in endemic regions (Thompson 2011). In fact, endemic mycoses are important, but often overlooked causes of community-acquired pneumonia and delays in recognition, diagnosis and proper treatment frequently lead to disastrous outcomes (Hage et al. 2012). Therefore, comprehension of the varied aspects of coccidioidomycosis remains a challenge that requires ongoing investigation, particularly in regions endemic for this mycosis.

\section{REFERENCES}

Altschul SF, Gish W, Miller W, Myers EW, Lipman EW 1990. Basic local alignment search tool. J Mol Biol 215: 403-410.

Ampel NM 2010. New perspectives on coccidioidomycosis. Proc Am Thorac Soc 7: 181-185.

Brilhante RSN, Cordeiro RA, Rocha MFG, Fechine MAB, Furtado FM, Nagao-Dias AT, Camargo ZP, Sidrim JJC 2008. Coccidioidal pericarditis: a rapid presumptive diagnosis by an in-house antigen confirmed by mycological and molecular methods. $J$ Med Microbiol 57: 1288-1292.

Capilla J, Clemons KV, Liu M, Levine HB, Stevens DA 2009. Saccharomyces cerevisiae as a vaccine against coccidioidomycosis. Vaccine 27: 3662-3668.

Castanon-Olivares LC, Güerena-Elizalde D, Gonzalez-Martinez MR, Licea-Navarro AF, Gonzalez-Gonzalez GM, Aroch-Calderon A 2007. Molecular identification of Coccidioides isolates from Mexican patients. Ann N Y Acad Sci 1111: 326-335.

Cordeiro RA, Brilhante RSN, Rocha MFG, Bandeira SP, Fechine MAB, Camargo ZP, Sidrim JJC 2010. Twelve years of coccidioidomycosis in Ceará state, Northeast Brazil: epidemiologic and diagnostic aspects. Diag Microb Infec Dis 66: 65-72.

Cordeiro RA, Brilhante RSN, Rocha MFG, Fechine MAB, Camara LMC, Camargo ZP, Sidrim JJC 2006a. Phenotypic characterization and ecological features of Coccidioides spp from Northeast Brazil. Med Mycol 44: 631-639.

Cordeiro RA, Brilhante RSN, Rocha MFG, Fechine MAB, Costa AKF, Camargo ZP, Sidrim JJC 2006b. In vitro activities of caspofungin, amphotericin B and azoles against Coccidioides posadasii strains from Northeast, Brazil. Mycopathologia 161: 21-26.

Crum NF, Potter M, Pappagianis D 2004. Seroincidence of coccidioidomycosis during military desert training exercises. $J$ Clin Microbiol 42: 4552-4555.
Egeberg RO, Elconin AE, Egeberg MC 1964. Effect of salinity and temperature on Coccidioides immitis and three antagonistic soil saprophytes. J Bacteriol 88: 473-476.

Elconin AF, Egberg RO, Egberg MC 1964. Significance of soil salinity on the ecology of Coccidioides immitis. J Bacteriol 87: 500-503.

Greene DR, Koenig G, Fisher MC, Taylor JW 2000. Soil isolation and molecular identification of Coccidioides immitis. Mycologia 92: 406-410.

Hage CA, Knox KS, Wheat LJ 2012. Endemic mycoses: overlooked causes of community acquired pneumonia. Respir Med 106: 769-776.

IPECE - Instituto de Pesquisa e Estratégia Econômica do Ceará, Secretaria de Planejamento e Gestão (SEPLAG) Governo do Estado do Ceará 2007. Ceará em mapas. Available from: 2.ipece. ce.gov.br/atlas/.

Kim SY, Shin AR, Kim HJ, Cho SN, Park JK, Shin SJ 2009. Identification of Rv2041c, a novel immunogenic antigen from Mycobacterium tuberculosis with serodiagnostic potential. Scand J Immunol 70: 457-464.

Kwok HKH, Chan JWM, Li IWS, Chu SYY, Lam CW 2009. Coccidioidomycosis as a rare cause of pneumonia in non-endemic areas: a short exposure history should not be ignored. Respirology 14: 617-620.

Lauer A, Baal JD, Baal JC, Verma M, Chen JM 2012. Detection of Coccidioides immitis in Kern County, California, by multiplex PCR. Mycologia 104: 62-69.

Macêdo RCL, Rosado AS, Mota FF, Cavalcante MAS, Eulálio KD, Filho AD, Martins LMS, Lazéra MS, Wanke B 2011. Molecular identification of Coccidioides spp in soil samples from Brazil. BMC Microbiol 11: 108-116.

Saubolle MA, McKellar PP, Sussland D 2007. Epidemiologic, clinical and diagnostic aspects of coccidioidomycosis. J Clin Microbiol 45: $26-30$.

Schneider E, Hajjeh RA, Spiegel RA, Jibson RW, Harp EL, Marshall GA, Gunn RA, McNeil MM, Pinner RW, Baron RC, Burger RC, Hutwagner LC, Crump C, Kaufman L, Reef SE, Feldman GM, Pappagianis D, Werner SB 1997. A coccidioidomycosis outbreak following the Northridge, Calif, earthquake. JAMA 277: 904-908.

Sidrim JJC, Silva LCI, Nunes JMA, Rocha MFG, Paixão GC 1997. Le Nord-Est Bresilien, Region dendemie de coccidioidomycose? A propos dune micro-epidemie. J Mycol Med 7: 37-39.

Stern NG, Galgiani JN 2010. Coccidioidomycosis among scholarship athletes and other college students, Arizona, USA. Emerg Infect Dis 16: 321-323.

Thompson GR 2011. Pulmonary coccidiodiomycosis. Semin Respir Crit Care Med 32: 754-763.

Umeyama T, Sano A, Kamei K, Niimi M, Nishimura K, Uehara Y 2006. Novel approach to designing primers for identification and distinction of the human pathogenic fungi Coccidioides immitis and Coccidioides posadasii by PCR amplification. J Clin Microbiol 44: 1859-1862.

White TJ, Bruns T, Lee S, Taylor JW 1990. Amplification and direct sequencing of fungal ribosomal RNA genes for phylogenetics. In M Innisle, T White, JJ Sninsky, PCR protocols: a guide to methods and applications, Academic Press, San Diego, p. 315-322. 